\title{
Thermo-mechanical response of FG tungsten/EUROFER multilayer under high thermal loads
}

\author{
D.D. Qu ${ }^{\text {a, b, * }, ~ M . ~ W i r t z ~}{ }^{c}$, J. Linke $^{c}$, R. Vaßen ${ }^{c}$, J. Aktaa $^{\mathrm{a}}$ \\ ${ }^{a}$ Karlsruhe Institute of Technology, Institute for Applied Materials, Hermann-von-Helmholtz-Platz 1, 76344, Eggenstein-Leopoldshafen, Germany \\ ${ }^{\mathrm{b}}$ Institute of Mechanics, Chinese Academy of Sciences, Beijing, 100190, China \\ ${ }^{c}$ Forschungszentrum Jülich GmbH, Institut für Energie- und Klimaforschung, 52425, Jülich, Germany
}

\section{A R T I C L E I N F O}

\section{Article history:}

Received 22 June 2018

Received in revised form

12 March 2019

Accepted 12 March 2019

Available online 15 March 2019

\section{Keywords:}

Functionally graded material (FGM)

Tungsten

EUROFER

Multilayer

ELMs-like heat load

Damage threshold

Residual stress

\begin{abstract}
A B S T R A C T
With the aim to evaluate the performance of functionally graded (FG) tungsten/EUROFER multilayer under fusion relevant transient heat loads, this study summarizes the experimental results on type-I edge localized mode (ELM)-like thermal shock exposures of a FG tungsten/EUROFER multilayer. Absorbed power densities of 0.19 and $0.38 \mathrm{GW} / \mathrm{m}^{2}$ with a pulse duration of $1 \mathrm{~ms}$, and base temperatures of room temperature and $550^{\circ} \mathrm{C}$ were chosen. We assessed the effect of variable FG-layers that consisted of three designed thicknesses and two kinds of layer numbers. The conclusion is that the introduction of FG-layers improves the thermal shock resistance. The thermal shock crack thresholds at RT and $550{ }^{\circ} \mathrm{C}$ of five multilayers lie between 0.19 and $0.38 \mathrm{GW} / \mathrm{m}^{2}$.
\end{abstract}

๑) 2019 Elsevier B.V. All rights reserved.

\section{Introduction}

A tungsten (W) coating is considered to protect the first wall (FW) in the current European DEMO blanket concepts [1], due to its favorable properties, e.g. high temperature strength, low sputtering yield and low activation [2,3]. Reduced activation Ferritic/ Martensitic (RAFM) steel, e.g. EUROFER, is a promising structural material for the FW application [4]. A FG-layer was introduced to reduce the mismatch of thermo-physical properties between tungsten and EUROFER that could lead to large residual thermal stresses and even failure [5].

The potential for the FG W/EUROFER in reducing inelastic strains and improving the lifetime was demonstrated [5,6], and non-linear finite element simulation results indicated values for the herein investigated thicknesses of FG-layers [5]. Based on the simulation results, a tungsten coating with a FG tungsten/EUROFER layer on a EUROFER substrate (FG tungsten/EUROFER multilayer) was fabricated by vacuum plasma spraying (VPS) [7]. VPS was chosen for

\footnotetext{
* Corresponding author. Institute of Mechanics, Chinese Academy of Sciences, Beijing, 100190, China

E-mail address: dandanqu@imech.ac.cn (D.D. Qu).
}

fabricating FG tungsten/EUROFER multilayer owing to the ability to achieve a full range of graded chemical composition, in-situ repairing as well as the avoidance of oxide formation $[6,8,9]$ and a large area with a relatively high coating rate [10]. The FG tungsten/EUROFER multilayers have the expected nominal microstructure of thermal spraying coatings with pancake-like features, columnar grains, as well as low porosity and sound, almost seamless interfaces between the FG-layer and the EUROFER substrate [7].

The FW in future DEMO-type devices has to withstand extreme thermal operating conditions, including steady state (up to $1 \mathrm{MWm}^{-2}$ ) and transient thermal loads (e.g. ELMs, up to $1 \mathrm{GWm}^{-2}$ ) [11]. Therefore, it is critical to evaluate thermal response of FW components. The thermal response of tungsten armor coatings on RAFM steel has been investigated and reported in Refs. [12-14]. Atmospheric plasma spraying (APS)-W and VPS-W coatings started to melt above 0.38 and $0.56 \mathrm{GW} / \mathrm{m}^{2}$, respectively. The coatings began to show cracking at lower power densities, 0.19 and $0.38 \mathrm{GW} /$ $\mathrm{m}^{2}$ [12]. However, the delamination occurred near the interface between the VPS-W coating and the RAFM substrate and was induced by the thermal stresses [14]. The thermal response of FG tungsten/EUROFER multilayers needs be investigated further. 
Table 1

The sample fabrication varieties and experimental conditions of the heat loads.

\begin{tabular}{|c|c|c|c|c|}
\hline Specimen identifier & FG layer number & FG-layer thickness $/ \mu \mathrm{m}$ & Heat flux power density $/ \mathrm{GW} / \mathrm{m}^{2}$ & Base temperature \\
\hline $3-\mathrm{T}(300)$ & 3 & 341.1 & $0.19 ; 0.38$ & RT and $550^{\circ} \mathrm{C}$ \\
\hline $3-\mathrm{T}(500)$ & 3 & 527.6 & $0.19 ; 0.38$ & RT and $550^{\circ} \mathrm{C}$ \\
\hline $3-\mathrm{T}(700)$ & 3 & 862.5 & $0.19 ; 0.38$ & $\mathrm{RT}$ and $550^{\circ} \mathrm{C}$ \\
\hline $5-\mathrm{T}(500)$ & 5 & 638.8 & $0.19 ; 0.38$ & RT and $550^{\circ} \mathrm{C}$ \\
\hline $5-\mathrm{T}(700)$ & 5 & 935.5 & $0.19 ; 0.38$ & RT and $550^{\circ} \mathrm{C}$ \\
\hline
\end{tabular}

In this paper, we performed ELM-like extreme heat load experiments on FG tungsten/EUROFER multilayers and analyzed the crack characteristics of exposed surfaces and cross-sections.

\section{FG W/EUROFER multilayer and experimental details}

FG W/EUROFER multilayer samples consisted of an EUROFER substrate, either three or five layers of varying $\mathrm{W}$ to EUROFER ratio composition, and finally a $\sim 500 \mu \mathrm{m}$ thick deposited tungsten layer on the surface. An F4 plasma gun from Sulzer-Metco was utilized to perform VPS. Five different FG-layer versions (variable thicknesses and layer numbers) showed in Table 1 were deposited on EUROFER substrates by VPS. All had the same pure tungsten coating on top of the FG layers. For the formation of each FG-layer, both tungsten and EUROFER powders were injected synchronously from two nozzles with a power of $50 \mathrm{KW}$ and a velocity of several $100 \mathrm{~m} / \mathrm{s}$, melted and mixed before they solidified on the substrate. The deposition rate was up to $0.5 \mathrm{~kg} / \mathrm{min}$, and the substrate was preheated to a temperature of $\sim 750^{\circ} \mathrm{C}$ before the spraying process.

The optimized spraying parameters and the vacuum condition caused good melting and re-solidification of powders and produced a low porosity of multilayers. In particular, the porosity of $\mathrm{W}$ coating was $4 \%$ according to the image analyses, and that of the FGlayer was less than $2 \%$ [15]. Three or five layers of varying $\mathrm{W}$ to
EUROFER composition were deposited to form the FG section. This discrete layer method was used because a continuous variation of composition was not feasible with this fabrication process. The true concentrations of tungsten in each FG-layer were measured and introduced in Refs. [7,15]. The cross-section in Fig. 1(a) shows the microstructure of a multilayer with five stepwise layers. The volume concentration of tungsten in the FG-layer gradually increases from the substrate to the tungsten coating. In addition, Fig. 1 (b) shows a higher magnification image of the pure tungsten coating, which has a large proportion of columnar grains with an aspect ratio of about 3.9. Cross-section was directly vertical perpendicular to the surface and it was prepared with mechanical polishing. The thickness of the tungsten coating was designed to be $500 \mu \mathrm{m}$ for all the samples, while the nominal thicknesses of the FG-layers were designed to be 300,500 and $700 \mu \mathrm{m}$ according to the simulation results [5]. True thicknesses of each FG-layer were measured on cross-section images and the whole multilayers were comparable but a bit larger than the nominal ones.

The electron beam facility JUDITH 1 [16] from Forschungszentrum Jülich(FZJ) was used to perform thermal shock tests of the FG W/EUROFER multilayer materials. JUDITH 1 is capable of simulating fusion relevant steady-state heat loads as well as transient events such as ELMs, VDEs, and plasma disruptions.
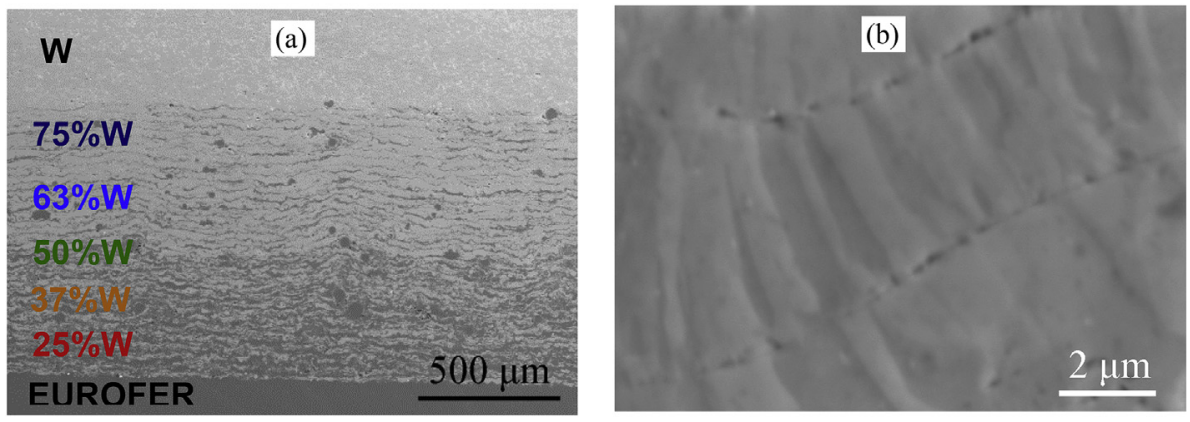

Fig. 1. (a) Cross-section image of a FG W/EUROFER multilayer with five layers of varying composition. (b) Magnification of a pure tungsten coating
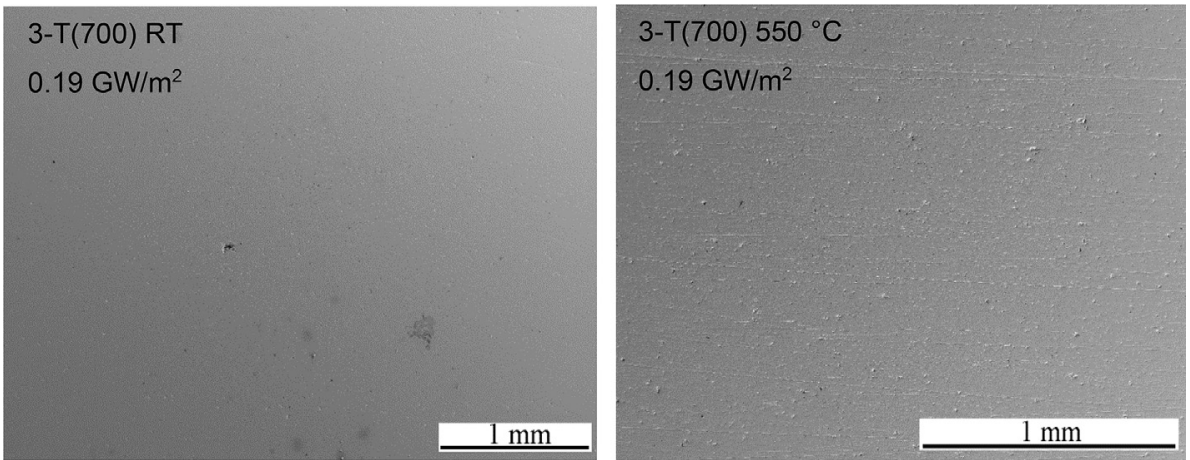

Fig. 2. The surface of sample 3-T(700) exposed to the power density of $0.19 \mathrm{GW} / \mathrm{m}^{2}$ at $\mathrm{RT}$ and $550^{\circ} \mathrm{C}$. 

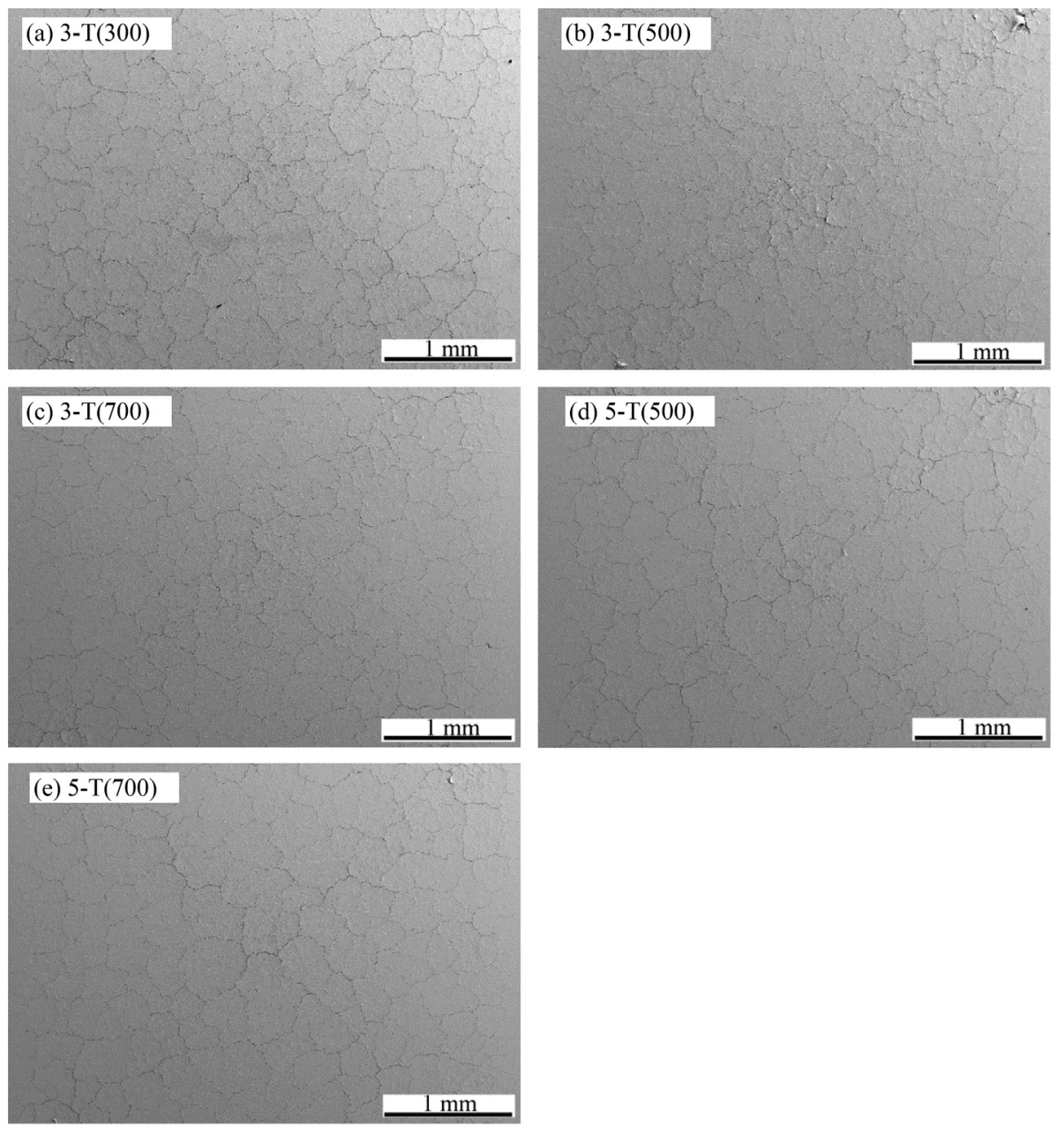

Fig. 3. The resulting surface damages of different samples exposed to the power density of $0.38 \mathrm{GW} / \mathrm{m}^{2}$ at RT.

In JUDITH 1, a homogeneous heat load distribution of a $4 \times 4 \mathrm{~mm}^{2}$ loaded area is achieved by a scanning of the Gaussian shaped $1 \mathrm{~mm}$ wide electron beam. All five samples were cut into $50 \mathrm{~mm} \times 10 \mathrm{~mm}$ sections, and then the top surfaces were ground to a mirror finish to create a well-defined starting state. The samples were loaded with ELM-like relevant power densities of 0.19 and $0.38 \mathrm{GW} / \mathrm{m}^{2}$. The power densities were obtained by taking an electron absorption coefficient of 0.46 into account. A focused electron beam scanned the exposed area at very high scanning frequencies $(47 \mathrm{kHz}$ in the $\mathrm{x}$-direction and $43 \mathrm{kHz}$ in the $\mathrm{y}$-direction), a single pulse duration of $1 \mathrm{~ms}$ and a total number of 100 pulses. In addition to tests performed at room temperature (RT), a graphite holder with a tubular heating cartridge was used to achieve base temperatures of up to $550^{\circ} \mathrm{C}$ [17].

The induced thermal shock damages were investigated by scanning electron microscope (SEM), optical microscope (OM), as well as focused ion beam (FIB) for cutting into certain interesting cracks. To quantify the surface morphology (roughening and cracks), erosion and redeposition, a profilometer with a confocal sensor (KF3 by OPM GmbH) was used. The sensor is able to determine the vertical position of the surface with a precision of up to $0.02 \mu \mathrm{m}$. Line scans or 3D-surface profiles can be recorded using a rapid stage positioning system (up to $10 \mathrm{~mm} / \mathrm{s}$ ). The maximum measurement frequency is $1 \mathrm{kHz}$. The maximum travel distance of the stage positioning system is limited to 50 and $100 \mathrm{~mm}$ in the $\mathrm{x}$ and y-direction, respectively. The pressure in the chamber is around $10^{-4}$ mbar. The maximum measurement range of the $z-$ direction is $1 \mathrm{~mm}$. The system is qualified to measure the micromorphological characteristics of polished samples' surfaces before and after thermal loads tests. This procedure enables to differentiate the kind of surface damage/modification induced by transient or steady state heat loads. A value of the surface roughness via the profilometry measurement is utilized to classify and compare the results and their dependence on the materials and testing conditions. The samples were attached to the sample holder by conducting carbon cement (conduct-c) to improve the thermal contact. The samples are passively cooled, in addition, the base temperature was monitored by an IR camera (not recorded) to ensure that there is no pile up of the temperate during loading. The time between two thermal shocks was long enough to allow the sample a cool down back to the initial base temperature.

\section{Results and discussion}

\subsection{Exposed surface morphology}

Fig. 2 shows the surfaces of 3-T(700) exposed to the power density of $0.19 \mathrm{GW} / \mathrm{m}^{2}$ at the base temperatures of RT and $550{ }^{\circ} \mathrm{C}$. There is no damage on the surfaces of all five samples irrespective of the base temperature of at RT or $550^{\circ} \mathrm{C}$, so only the sample 3$\mathrm{T}(700)$ is shown as an example. However, a dense crack network is observed for all five samples on exposed surfaces when the 

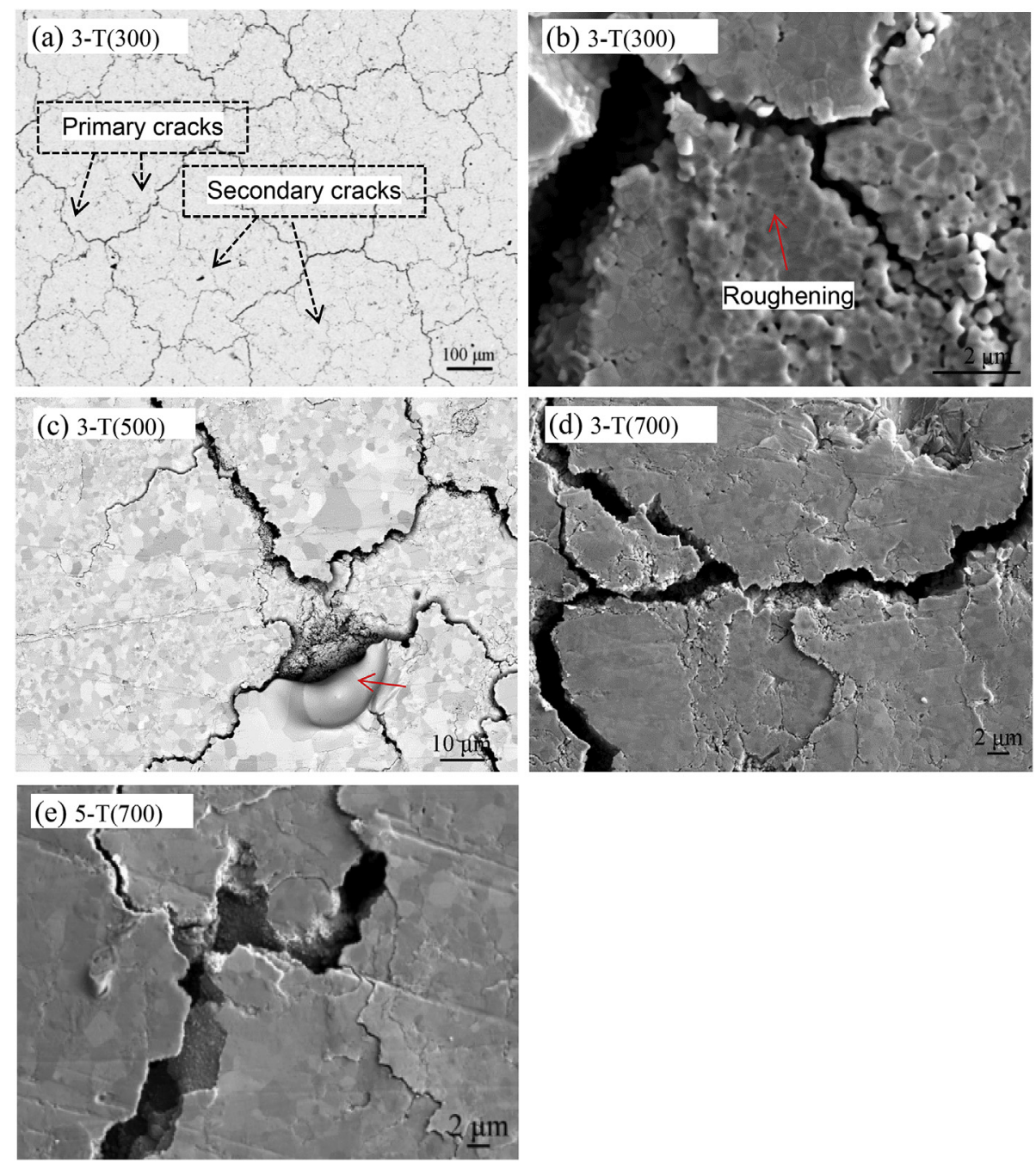

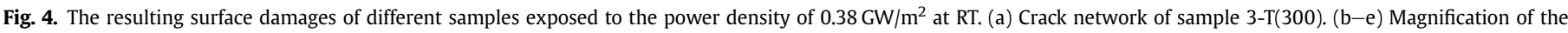
cracks on the samples 3-T(300), 3-T(500), 3-T(700) and 5-T(700), respectively.

power density is increased to $0.38 \mathrm{GW} / \mathrm{m}^{2}$, as shown in Fig. 3 . Typical primary and secondary cracks induced by the thermal shock test are observed and shown in Fig. 4 (a), taking sample 3$\mathrm{T}(300)$ as an example. The magnifications of primary cracks in Fig. 4 (b), (d) and (e) show that the width of the primary crack is in a range of $1.5-3 \mu \mathrm{m}$. These cracks formed most likely due to the brittleness of the material in the first few shots. The temperature of the exposed surface can increase several hundred Kelvins in the thickness range of several tens of micrometers, then an irreversible swelling (up to a few micrometers) and a roughening of the surface can be observed. The temperature rise of several hundred Kelvins is calculated on the basis of the heat-diffusion equation for undamaged bulk tungsten. However, for the damaged surface, the temperature could be very high due to the reduction of the thermal conductivity. For instance, the temperature of recrystallized tungsten exposed to $0.38 \mathrm{GW} / \mathrm{m}^{2}$ heat load could be up to $\approx 2500^{\circ} \mathrm{C}$ based on FE simulation [18]. Obvious surface roughening is shown in Fig. 4 (b), even partial melting occurs at the crack edge in Fig. 3 (c).

As showed in Fig. 5, a denser crack network is observed on the surfaces exposed to absorbed power density of $0.38 \mathrm{GW} / \mathrm{m}^{2}$ at $550{ }^{\circ} \mathrm{C}$ comparing to that at RT. Fig. 6 (a) shows the primary and secondary cracks, and double-headed arrows illustrate how crack distances were measured. Grain growth is observed around the crack edge, as showed in the red dotted lines in Fig. 6 (b), (c), which is due to the overheating of the local area. The propagation of cracks under the surface is disclosed by FIB cutting, as shown in Fig. 6 (d), (e). The crack propagates initially perpendicular to the loaded surface into the sample, and then deflects to the parallel direction or at an angle of $\sim 45^{\circ}$ to the loaded surface at a certain depth. Cracks extending partially or fully parallel to the loaded area act as thermal barriers, leading to the overheating of the local area. Severe overheating can even introduce molten edges, as showed in Fig. 6 (f).

\subsection{Crack characteristics}

The crack distances (distance between adjacent primary cracks as shown in Fig. 6 (a)) were measured on the surfaces of five samples that were exposed to $0.38 \mathrm{GW} / \mathrm{m}^{2}$ at RT and $550{ }^{\circ} \mathrm{C}$. Ten values of crack distance were measured on each sample surface. The crack distances at RT were in the range of $400-500 \mu \mathrm{m}$ and they were higher compared to $550^{\circ} \mathrm{C}$. The reciprocal of the crack distance between adjacent cracks was defined to be the crack density [17]. Fig. 7 shows the crack density values of samples exposed to the power density of $0.38 \mathrm{GW} / \mathrm{m}^{2}$. The crack density for 

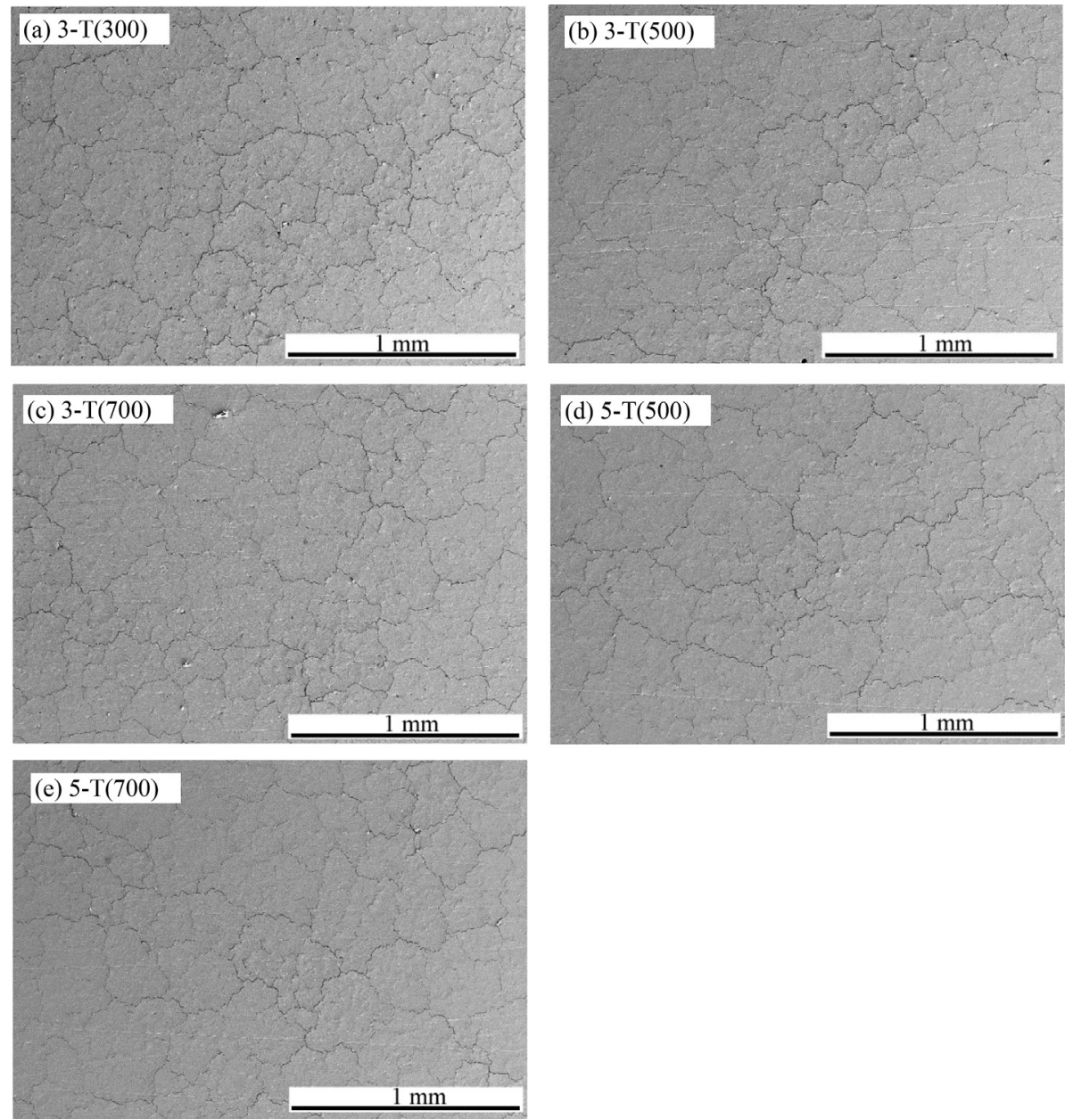

Fig. 5. The resulting surface damages of different samples exposed to the power density of $0.38 \mathrm{GW} / \mathrm{m}^{2}$ at $550^{\circ} \mathrm{C}$.

samples with a base temperature of $550{ }^{\circ} \mathrm{C}$ decreases with an increasing FG-layer thickness up to $\sim 0.7 \mathrm{~mm}$ thickness. The effective thickness from the exposed surface to the bulk is only in the range of several tens of micrometers, which lies in the W coating of the five samples. Therefore, influence of FG-layer's thickness on the crack density is assumed to be owing to the reduction of residual stress in the $\mathrm{W}$ coating, specifically for the $0.7 \mathrm{~mm}$ thick FG-layer. The influence of the stress state on the thermal shock resistance of recrystallized tungsten was discussed in Ref. [19]. In addition to the residual stress in $\mathrm{W}$ coating, the temperature and strain rate also affected the crack density $[17,20]$. The crack density in materials exposed to $0.38 \mathrm{GW} / \mathrm{m}^{2}$ at $550{ }^{\circ} \mathrm{C}$ was higher than that at RT. The width of primary cracks was in the range of $1.5-3 \mu \mathrm{m}$.

The y-axis in Fig. 8 is defined by the ratio of exposed surface's roughness divided by as-received surface's roughness. The roughness ratio is almost equal to 1 in the case of the surfaces exposed to the low power density at both temperatures, which mean no surface damage. While with regard to the surfaces exposed to the high power density, the ratio is higher than 1 due to the surface roughening and cracking. In addition, the ratio decreases with the increasing thickness of the FG-layer at RT, particularly when the FGlayer thickness is less than $0.7 \mathrm{~mm}$. For the case of $550^{\circ} \mathrm{C}$, it decreases when the FG-layer thickness is larger than $0.3 \mathrm{~mm}$. According to the analysis of the microstructure and the crack characteristics, the damage threshold of the multilayer is determined to be the range of 0.19 and $0.38 \mathrm{GW} / \mathrm{m}^{2}$, as shown in Fig. 9 .
After exposing the five samples to the same thermal loads of 100 pulses and $1 \mathrm{~ms}$ duration, the crack thresholds lie between 0.19 and $0.38 \mathrm{GW} / \mathrm{m}^{2}$, that are comparable to pure bulk $\mathrm{W}$ and $\mathrm{W}$-UHP in Refs. [22-24]. The satisfying thermal shock resistance of the multilayer might be due to the low porosity of the multilayer $(<4 \%)$ [7,15], the microstructure characteristics of the VPS coating including the laminar structure and columnar grains [7,15], as well as the reduction or redistribution of the residual stress $[5,15]$.

Low porosity means high density and good thermal conductivity that is beneficial for the heat transfer from the loaded surface into the bulk of the sample. The effect of porosity on the crack threshold of a W coating was studied in Ref. [12]. Coatings of APS-W and VPS$\mathrm{W}$ with porosities of $6 \%$ and $0.6 \%$ started to crack at the power densities of 0.19 and $0.38 \mathrm{GW} / \mathrm{m}^{2}$, respectively.

The effect of the grain orientation and microstructure on how cracks grow was discussed in Ref. [17]. Longitudinal specimens (grains elongated parallel to the loaded surface) and the recrystallized specimens (heat treated longitudinal specimens) showed an arbitrary crack network as the thermal shock crack pattern within the loaded area. The thermal shock cracks of the transversal (grains elongated perpendicular to the loaded surface) followed the grain orientation. The investigation of cross-section images also proved that cracks of longitudinal and recrystallized specimens grew perpendicular to the loaded surface into the material and changed direction at a certain depth where they propagated parallel to the surface. However, cracks of transversal specimens 

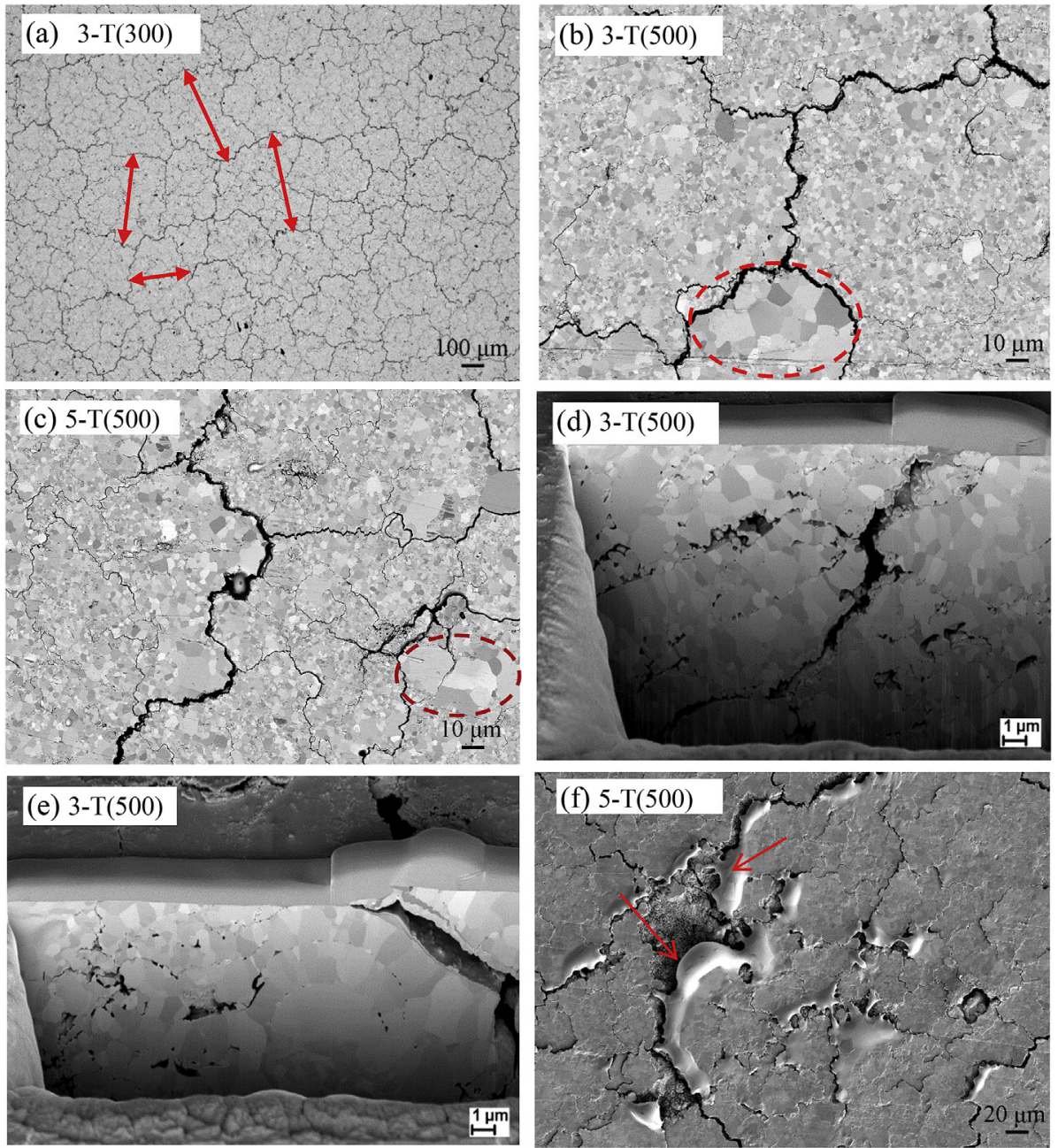

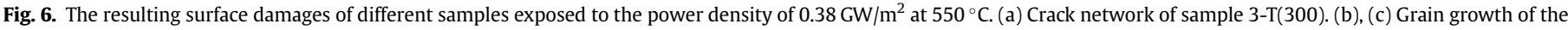
sample 3-T(500) and 5-T(500), respectively. (d), (e) Cracks below the surface of sample 3-T(500). (f) Melted edges of sample 5-T(500).

always propagated perpendicular to the loaded surface and grew along the grain boundaries [17]. For W/EUROFER multilayers, the

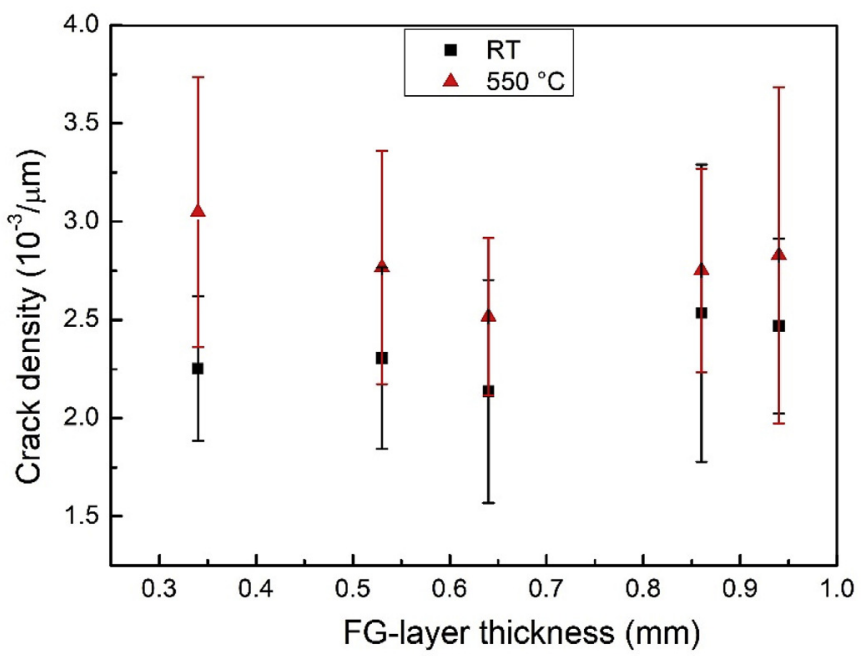

Fig. 7. Crack density values for samples exposed to the power density of $0.38 \mathrm{GW} / \mathrm{m}^{2}$ at the base temperatures of RT and $550^{\circ} \mathrm{C}$, respectively. grain orientation is a mixture of a longitudinal laminar pancakelike structure and transversal columnar grains. However, the cracks follow the longitudinal direction, since small pores among the laminar pancake-like structure lead to the laminar interfaces being weaker than columnar grain boundaries. Although cracking parallel to the loaded surface may lead to the overheating of the top thin layer, the columnar grain structure could be helpful to avoid the reduction of thermal transfer and subsequent delamination.

The theoretical reason for cracks being induced by thermal shock tests is that tensile stresses arise during the cooling process. Specifically, due to the high heat flux, the temperature in the loaded area could increase from several hundred to $2000^{\circ} \mathrm{C}$ [21] and thereby cross the ductile-brittle transition temperature (DBTT) of the material. The thermally induced expansion and the plastic deformation of the affected material occur due to compressive stresses. When the temperature decreases to the initial value, the thermal contraction happens and causes tensile stresses. The tensile stresses lead to the formation of cracks [22]. Compared to RT, the worse performance at $550{ }^{\circ} \mathrm{C}$ is related to the lower yield strength of tungsten at higher temperatures, which lead to increased plastic deformation.

Several kinds of $\mathrm{W}$ coatings behave differently after exposure to different thermal loads [12-14,25-27]. Even if the thermal shock resistance could be improved just by optimizing the coating quality, 

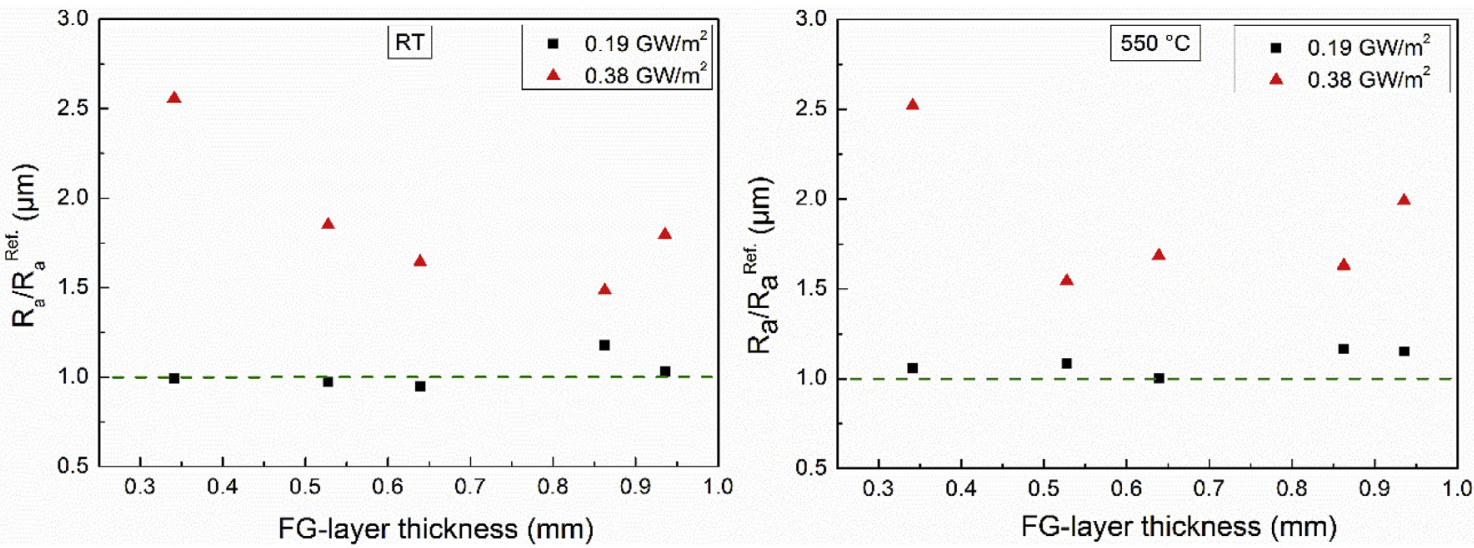

Fig. 8. Roughness comparison before and after exposure to the power densities of 0.19 and $0.38 \mathrm{GW} / \mathrm{m}^{2}$ at the base temperatures of RT and $550{ }^{\circ} \mathrm{C}$.

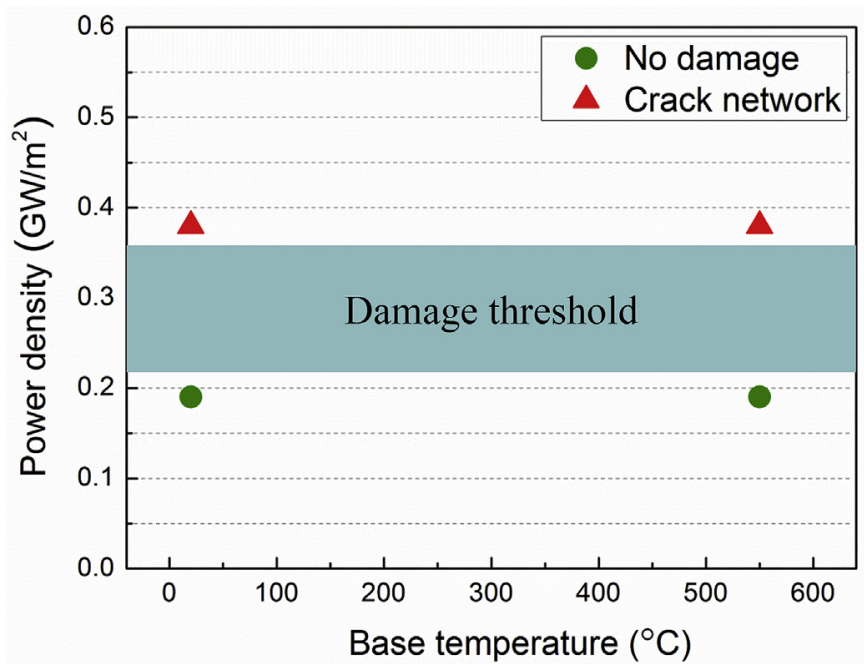

Fig. 9. Thermal shock response of multi-layered FG samples after 100 thermal shock events at different power densities and base temperatures.

there would still be large residual stresses present in coatings without any interlayers. This could lead to delamination and severe failure of the whole coating [14]. The tensile stresses can lead to cracking. The reduction of residual stress in $\mathrm{W}$ coatings may release the tensile stress.

\section{Conclusion}

The samples with three layers and the samples with five layers as FG-layer show a comparable thermal shock resistance, despite the fact that a higher resistance was expected for the five layer system. Since samples with five layers as FG-layer show only a slightly smoother gradient than those with three layers, it seems insufficient to show the advantages of a smoother gradient. In addition, the application of the FG-layer reduces the inelastic strain induced by thermal cycles. Less inelastic strain is beneficial for the improvement of the mechanical properties of the multilayer and thereby improving the crack resistance. Current FG W/EUROFER multilayers show a promising performance. However, the further work on the thermal load resistance of FG W/EUROFER multilayers for the FW with cooling channels is needed to investigate the feasibility for fusion application.

\section{Acknowledgment}

This work has been carried out within the framework of the EUROfusion Consortium and has received funding from the Euratom research and training programme 2014-2018 under grant agreement no. 633053. The views and opinions expressed herein do not necessarily reflect those of the European Commission. This work was supported by the National Natural Science Foundation of China under grant No. 11802309.

\section{References}

[1] L.V. Boccaccini, G. Aiello, J. Aubert, C. Bachmann, T. Barrett, A. Del Nevo, D. Demange, L. Forest, F. Hernandez, P. Norajitra, G. Porempovic, D. Rapisarda, P. Sardain, M. Utili, L. Vala, Objectives and status of EUROfusion DEMO blanket studies, Fusion Eng. Des. 109-111 (2016) 1199-1206.

[2] M. Rieth, S.L. Dudarev, S.M.G. de Vicente, J. Aktaa, T. Ahlgren, S. Autusch, D.E.J. Armstrong, M. Balden, N. Baluc, M.F. Barthe, W.W. Basuki, M. Battabyal, C.S. Becquart, D. Blagoeva, H. Boldyryeva, J. Brinkmann, M. Celino, L. Ciupinski, J.B. Correia, A. De Backer, C. Domain, E. Gaganidze, C. Garcia-Rosales, J. Gibson, M.R. Gilbert, S. Giusepponi, B. Gludovatzj, H. Greuner, K. Heinola, T. Hoschen, A. Hoffmann, N. Holstein, F. Koch, W. Krauss, H. Li, S. Lindig, J. Linke, C. Linsmeier, P. Lopez-Ruiz, H. Maier, J. Matejicek, T.P. Mishra, M. Muhammed, A. Munoz, M. Muzyk, K. Nordlund, D. Nguyen-Manh, J. Opschoor, N. Ordas, T. Palacios, G. Pintsuk, R. Pippan, J. Reiser, J. Riesch, S.G. Roberts, L. Romaner, M. Rosinski, M. Sanchez, W. Schulmeyer, H. Traxler, A. Urena, J.G. van der Laan, L. Veleva, S. Wahlberg, M. Walter, T. Weber, T. Weitkamp, S. Wurster, M.A. Yar, J.H. You, A. Zivelonghi, Recent progress in research on tungsten materials for nuclear fusion applications in Europe, J. Nucl. Mater. 432 (1-3) (2013) $482-500$.

[3] J. Aktaa, W.W. Basuki, T. Weber, P. Norajitra, W. Krauss, J. Konys, Manufacturing and joining technologies for helium cooled divertors, Fusion Eng. Des. 89 (2014) 913-920.

[4] A. Kohyama, A. Hishinuma, D.S. Gelles, R.L. Klueh, W. Dietz, K. Ehrlich, Lowactivation ferritic and martensitic steels for fusion application, J. Nucl. Mater. 233-237 (1996) 138-147.

[5] D.D. Qu, W.W. Basuki, J. Aktaa, Numerical assessment of functionally graded tungsten/steel multilayer for first wall applications, Fusion Eng. Des. 98-99 (2015) 1389-1393.

[6] T. Weber, J. Aktaa, Numerical assessment of functionally graded tungsten/steel joints for divertor applications, Fusion Eng. Des. 86 (2011) 220-226.

[7] D.D. Qu, W.W. Basuki, J. Gibmeier, R. Vaßen, J. Aktaa, Development of functionally graded tungsten/EUROFER multilayer for first wall application, Fusion Sci. Technol. 68 (2015) 578-581.

[8] T. Weber, M. Stüber, S. Ulrich, R. Vaßen, W.W. Basuki, J. Lohmiller, W. Sittel, J. Aktaa, Functionally graded vacuum plasma sprayed and magnetron sputtered tungsten/EUROFER97 interlayers for joints in helium-cooled divertor components, J. Nucl. Mater. 436 (2013) 29-39.

[9] G. Thomas, Advanced Materials for Plasma Facing Components in Fusion Devices, Ph.D thesis, The Queen's College, 2009.

[10] T. Nagasaka, R. Kasada, A. Kimura, Y. Ueda, T. Muroga, Thermophysical properties and microstructure of plasma-sprayed tungsten coating on low activation materials, Fusion Sci. Technol. 56 (2009) 1053-1057.

[11] H. Bolt, V. Barabash, G. Federici, J. Linke, A. Loarte, J. Roth, K. Sato, Plasma facing and high heat flux materials-needs for ITER and beyond, J. Nucl. Mater. 307 (2002) 43-52.

[12] Y. Yahiro, M. Mitsuhara, K. Tokunakga, N. Yoshida, T. Hirai, K. Ezato, S. Suzuki, 
M. Akiba, H. Nakashima, Characterization of thick plasma spray tungsten coating on ferritic/martensitic steel F82H for high heat flux armor, J. Nucl. Mater. 386-88 (2009) 784-788.

[13] H. Greuner, H. Bolt, B. Boswirth, S. Lindig, W. Kuhnlein, T. Huber, K. Sato, S. Suzuki, Vacuum plasma-sprayed tungsten on EUROFER and 316L: results of characterisation and thermal loading tests, Fusion Eng. Des. 75-79 (2005) 333-338.

[14] K. Tokunaga, T. Hotta, K. Araki, Y. Miyamoto, T. Fujiwara, M. Hasegawa, K. Nakamura, K. Ezato, S. Suzuki, M. Enoeda, M. Akiba, T. Nagasaka, R. Kasada, A. Kimura, High heat loading properties of vacuum plasma spray tungsten coatings on reduced activation ferritic/martensitic steel, J. Nucl. Mater. 438 (2013) S905-S908

[15] D.D. Qu, Development of Functionally Graded Tungsten/EUROFER Multilayers, Ph.D thesis, Karlsruhe Institute of Technology (KIT), 2016.

[16] R. Duwe, W. Kuehnlein, H. Muenstermann, The New Electron Beam Facility for Materials 358

[17] M. Wirtz, G. Cempura, J. Linke, G. Pintsuk, I. Uytdenhouwen, Thermal shock response of deformed and recrystallised tungsten, Fusion Eng. Des. 88 (9-10) (2013) 1768-1772.

[18] J. Du, Y. Yuan, M. Wirtz, J. Linke, W. Liu, H. Greuner, FEM study of recrystallized tungsten under ELM-like heat loads, J. Nucl. Mater. 463 (2015) 219-222.

[19] Y. Yuan, J. Du, M. Wirtz, G.N. Luo, G.H. Lu, W. Liu, Surface damage and structure evolution of recrystallized tungsten exposed to ELM-like transient loads, Nucl. Fusion 56 (3) (2016), 036021.

[20] M. Wirtz, I. Uytdenhouwen, V. Barabash, F. Escourbiac, T. Hirai, J. Linke, Th Loewenhoff, S. Panayotis, G. Pintsuk, Material properties and their influence on the behaviour of tungsten as plasma facing material, Nucl. Fusion 57 (6) (2017), 066018.

[21] T. Hirai, N. Bekris, J.P. Coad, C. Grisolia, J. Linke, H. Maier, G.F. Matthews, V. Philipps, E. Wessel, Failure modes of vacuum plasma spray tungsten coating created on carbon fibre composites under thermal loads, J. Nucl. Mater. 392 (1) (2009) 40-44.

[22] J. Linke, T. Loewenhoff, V. Massaut, G. Pintsuk, G. Ritz, M. Roedig, A. Schmidt, C. Thomser, I. Uytdenhouwen, V. Vasechko, M. Wirtz, Performance of different tungsten grades under transient thermal loads, Nucl. Fusion 51 (2011), 073017.

[23] M. Wirtz, J. Linke, Th Loewenhoff, G. Pintsuk, I. Uytdenhouwen, Thermal shock tests to qualify different tungsten grades as plasma facing material, Phys. Scripta T167 (2016), 014015.

[24] M. Wirtz, J. Linke, Th Loewenhoff, G. Pintsuk, I. Uytdenhouwen, Transient heat load challenges for plasma-facing materials during long-term operation, Nucl. Mater. Energy 12 (2017) 148-155.

[25] J. Matejicek, Y. Koza, V. Weinzettl, Plasma sprayed tungsten-based coatings and their performance under fusion relevant conditions, Fusion Eng. Des. 75-79 (2005) 395-399.

[26] F.L. Chong, J.L. Chen, J.G. Li, Evaluation of tungsten coatings on CuCrZr and W Cu FGM under high heat flux and HT-7 limiter plasma irradiation, J. Nucl Mater. 363 (2007) 1201-1205.

[27] Y.Y. Lian, X. Liu, Z.K. Cheng, J. Wang, J.P. Song, Y. Yu, J.M. Chen, Thermal shock performance of CVD tungsten coating at elevated temperatures, J. Nucl. Mater. $455(1-3)(2014) 371-375$. 